OPEN ACCESS

Edited by: Fabian Cieplik,

University Medical Center Regensburg, Germany

Reviewed by: Denise Muehler, University Medical Center Regensburg, Germany Michael Pascoe, Cardiff University, United Kingdom

*Correspondence: Ana Pereira aalex@fe.up.pt

Specialty section: This article was submitted to Antimicrobials, Resistance and Chemotherapy, a section of the journa Frontiers in Microbiology

Received: 23 December 2021 Accepted: 27 January 2022

Published: 18 February 2022

Citation:

Barros AC, Melo LF and Pereira A (2022) A Multi-Purpose Approach to the Mechanisms of

Action of Two Biocides

(Benzalkonium Chloride and Dibromonitrilopropionamide):

Discussion of Pseudomonas fluorescens' Viability and Death.

Front. Microbiol. 13:842414. doi: 10.3389/fmicb.2022.842414

\section{A Multi-Purpose Approach to the Mechanisms of Action of Two Biocides (Benzalkonium Chloride and Dibromonitrilopropionamide): Discussion of Pseudomonas fluorescens' Viability and Death}

\author{
Ana C. Barros ${ }^{1,2}$, Luis F. Melo ${ }^{1,2}$ and Ana Pereira ${ }^{1,2 *}$ \\ 'LEPABE-Laboratory for Process Engineering, Environment, Biotechnology and Energy, Department of Chemical \\ Engineering, Faculty of Engineering, University of Porto, Porto, Portugal, ${ }^{2}$ ALiCE - Associate Laboratory in Chemical \\ Engineering, Faculty of Engineering, University of Porto, Porto, Portugal
}

Biocides are widely used in water treatment for microbiological control. The rise of antimicrobial resistance and the need to assure properly managed water systems require a better understanding of the mechanisms of action of biocides and of their impact on cell's viability as a function of dosage concentrations. The present work addresses these two aspects regarding the biocides benzalkonium chloride (BAC) and dibromonitrilopropionamide (DBNPA) - two biocides commonly found in the water treatment industry. For that, the following parameters were studied: culturability, membrane integrity, metabolic activity, cellular energy, and the structure and morphology of cells. Also, to assess cell's death, a reliable positive control, consisting of cells killed by autoclave (dead cells), was introduced. The results confirmed that BAC is a lytic biocide and DBNPA a moderate electrophilic one. Furthermore, the comparison between cells exposed to the biocides' minimum bactericidal concentrations (MBCs) and autoclaved cells revealed that other viability parameters should be taken into consideration as "death indicators." The present work also shows that only for the concentrations above the MBC the viability indicators reached values statistically similar to the ones observed for the autoclaved cells (considered to be definitively dead). Finally, the importance of considering the biocide mechanism of action in the definition of the viability parameter to use in the viable but non-culturable (VBNC) determination is discussed.

Keywords: benzalkonium chloride, dibromonitrilopropionamide, mechanism of action, viability, dead cells 


\section{INTRODUCTION}

For decades, biocides have been used in a wide range of applications, such as: water treatment, domestic environment, food preservation, healthcare sanitation, textile, and other industries to control and kill bacteria (Kahrilas et al., 2015; Jones and Joshi, 2021). Biocides are defined as substances with one or more active ingredients that are used to inactivate, prevent, or control any harmful microorganisms by chemical or biological ways (Ribeiro et al., 2018).

The same biocide can be used for several applications, sometimes by changing only the employed concentration. Additionally, biocides can have both bacteriostatic and bactericidal effects, which generally relies on the applied concentration (Denyer, 1990).

Although the final result can be the same (cell death), the mechanisms by which bacteria reach that state can be completely different. Many mechanisms of antimicrobial action were described and most times the antimicrobial action of a biocide is a combination of several mechanisms (Liwa and Jaka, 2015). What distinguishes the different mechanisms of action is the target site where they act. So, biocides can: (i) interfere with the replication of genetic information (nucleic acids); (ii) interfere with protein synthesis; (iii) alter structure and function of cell wall; (iv) increase permeability and disrupt the cytoplasmatic membrane; and (v) inhibit intermediate metabolic pathways (Liwa and Jaka, 2015).

In short, biocides can be classified in two main categories: electrophilic and membrane active biocides (Akhova and Tkachenko, 2014).

Electrophilic biocides include the extreme electrophilic (oxidants) and the moderate electrophilic (which includes most of the non-oxidizing biocides; Amjad, 2010; Bajpai, 2015). The oxidants, as the name suggests, oxidize organic material by either releasing toxic free radicals or by halogenating molecules within a cell, and have a rapid killing rate (Chapman, 2003; Amjad, 2010; Bajpai, 2015). The moderate electrophilic biocides interact with cellular nucleophiles by covalent linkage, which causes enzyme inactivation. Isothiazolones, dibromonitrilopropionamide (DBNPA), glutaraldehyde, formaldehyde, bronopol, and inorganic metallic ions (mercury, silver, and copper) fall in this category (Chapman, 2003; Paulus, 2005; Amjad, 2010; Bajpai, 2015).

The membrane active category includes the lytic biocides and the protonophores (Amjad, 2010; Bajpai, 2015). Lytic biocides, like quaternary ammonium compounds (QACs), alcohols, and biguanides, lead to cell lysis. They first interact with bacterial outer membrane and then with the cytoplasmatic membrane, which causes loss of integrity and leakage of intracellular components, followed by cell lysis (Paulus, 2005; Amjad, 2010). On the other hand, the protonophores includes weak acids, such as citric acid, benzoic acid, and sorbic acid. These biocides interfere with the $\mathrm{pH}$ balance of cells, which can cause cytoplasm acidification and consequent disruption of the proton-motive force. Thereby, the flow of protons across the cytoplasmatic membrane is compromised, meaning that cells cannot produce more energy (adenosine triphosphate, ATP) and that once the ATP sources end up, the cell has no more energy for its basic metabolism and starts to die (McDonnell, 2007; Amjad, 2010).
The current and wide spread use of disinfectant products containing low doses of biocides has raised some attention, as it can lead to the development of microbial tolerance to biocides and to the regrowth of microorganisms due to the inefficacy of the biocidal treatment (Maillard, 2005; Wesgate et al., 2016). The knowledge of the mechanisms of action of biocides is primordial to establish more accurate and rational disinfection strategies to combine different biocides to reinforce the antimicrobial activity and avoid potential tolerance mechanisms and toxicological effects.

The present work focuses on two commonly used biocides for industrial water treatment purposes [Benzalkonium chloride (BAC) and DBNPA], which have distinct modes of action. Benzalkonium chloride belongs to the family of QACs, meaning that they have a positively-charged quaternary amine group and one or two alkyl chains (Pati and Arnold, 2020). QACs are lytic cationic biocides which act through the interaction of their positively-charged part with the negatively-charged phospholipid bilayer of the bacterial cell membrane (Pati and Arnold, 2020). Additionally, membrane destabilization prompts cell lyses and intracellular components start to leak, leading to cell death (McDonnell, 2007; Gerba, 2015).

Dibromonitrilopropionamide is a moderate electrophilic biocide that interacts directly with cellular components (Siddiqui et al., 2017; Kucera, 2019). This biocide enters the cell by diffusion, thereby it takes a little longer to kill (Kucera, 2019). Its mechanism of action relies on the interaction with thiol groups of proteins (e.g., cysteine or glutathione). This reaction leads to the formation of disulphide bonds and the consequent irreversible protein damage. It also interferes with the transport across the cell and stops respiration and ATP synthesis (Ullah, 2011; Siddiqui et al., 2017; Kucera, 2019).

Although a significant number of authors have proposed hypotheses for the mechanism of action of DBNPA (Paulus, 2005; Williams and McGinley, 2010; Campa et al., 2019), there is a lack of studies based on a consistent set of assays to prove such hypotheses. So, the present paper aims to provide insights into the reported mechanisms of action of DBNPA. For that, Pseudomonas fluorescens cultures were exposed to different biocide concentrations, and several parameters evaluated, including: culturability, membrane integrity, metabolic activity, cellular energy, and morphological/structural changes. For comparison purposes, BAC was equally tested since its mechanism of action has been widely described in the literature (Chapman, 2003; Amjad, 2010; Bajpai, 2015). Furthermore, the antimicrobial activity of the biocides is here discussed against a negative control of live cells and a positive control of dead cells (by autoclaving). This strengthens the discussion by providing insights on the extent of the cell "damage" toward its dead state.

\section{MATERIALS AND METHODS}

\section{Biocides}

Benzalkonium chloride was purchased from Sigma-Aldrich. The biocide 2,2-Dibromo-3-nitrilopropionamide (DBNPA), 10\% $(\mathrm{w} / \mathrm{w})$ of active ingredient was provided by Enkrott ${ }^{\circledR}$, S.A. Stock 
solutions of the selected biocides were aseptically prepared in ultrapure water (UPW) and stored at $4^{\circ} \mathrm{C}$.

\section{Microorganisms and Culturing Conditions}

Pseudomonas fluorescens was isolated from a drinking water distribution system and identified by $16 \mathrm{~S}$ rRNA gene sequencing as described by Ferreira et al. (2009).

Bacterial cells were grown overnight in a batch culture in a nutrient medium with the following composition (per liter): $5 \mathrm{~g}$ glucose (Fisher Chemical), $2.5 \mathrm{~g}$ peptone (Oxoid), and $1.25 \mathrm{~g}$ yeast extract (Oxoid), in $0.02 \mathrm{M}$ phosphate buffer $\mathrm{pH} 7$ (KH2PO4; $\mathrm{Na} 2 \mathrm{HPO} 4)$ at $30^{\circ} \mathrm{C}$ and under agitation (160 rpm).

\section{Minimum Bactericidal Concentration Determination}

An overnight growth culture was harvested by centrifugation at $4,000 \mathrm{rpm}$ for $10 \mathrm{~min}$ and washed twice with sterile saline solution at $0.85 \%(\mathrm{v} / \mathrm{v})$. Then, bacteria were resuspended in saline solution and the optical density (at $610 \mathrm{~nm}$ ) adjusted to $0.2 \pm 0.02\left(1.3 \times 10^{8}\right.$ $\mathrm{CFU} / \mathrm{mL}$ ). The antimicrobial activity of biocides against planktonic bacteria was performed according to the European Standard EN 1276 (European Committee Standardisation, 2010) with some modifications. Bacterial cells $(100 \mathrm{~mL})$ were placed in $250-\mathrm{mL}$ flasks under agitation $(160 \mathrm{rpm})$ at $25^{\circ} \mathrm{C}$. For each biocide, different concentrations were tested (see section "Biocide Exposure"). The exposure times tested were: $0,0.17,0.5,1,5$, 15,30 , and $60 \mathrm{~min}$. At each time point an aliquot of $100 \mu \mathrm{l}$ was collected and subjected to a biocide neutralization step (10 min contact time) using a universal neutralizer: $3 \mathrm{~g} / \mathrm{L}$ of lecithin (Alfa Aesar), $30 \mathrm{~g} / \mathrm{L}$ of saponin (VWR Chemicals), $1 \mathrm{~g} / \mathrm{L}$ of L-histidine (Merck), $5 \mathrm{~g} / \mathrm{L}$ of sodium thiosulphate (Labkem), and $30 \mathrm{~g} / \mathrm{L}$ of polysorbate 80 (VWR Chemicals) in $0.0025 \mathrm{M}$ phosphate buffer. Afterward, the appropriate dilutions were performed and the cells plated on PCA plates and incubated at $30^{\circ} \mathrm{C}$. After $24 \mathrm{~h}$, the colony forming units (CFU) were enumerated. The minimum bactericidal concentration (MBC) was determined as the lower concentration able to kill $99.9 \%$ of bacteria (Parvekar et al., 2020) within $30 \mathrm{~min}$. Three independent experiments were performed for each condition.

\section{Mechanisms of Action of the Biocides Biocide Exposure}

Bacterial cells from an overnight culture were centrifuged (4,000 rpm, $10 \mathrm{~min})$ and washed with saline solution. Afterward, the optical density (at $610 \mathrm{~nm}$ ) was adjusted to $0.2 \pm 0.02$ in saline solution. Then, bacterial cells were placed in contact with the biocidal solutions for $30 \mathrm{~min}$ at $25^{\circ} \mathrm{C}$ and $160 \mathrm{rpm}$. Four different concentrations of each biocide were used, namely: the concentration determined as the $\mathrm{MBC}$, one concentration above the MBC, and two concentrations below the MBC. Therefore, the selected concentrations were $30,40,100$, and $160 \mathrm{mg} / \mathrm{L}$ for $\mathrm{BAC}$ and $5,8,10$, and $35 \mathrm{mg} / \mathrm{L}$ for DBNPA. Controls were performed with both live cells only (negative control) and dead cells only (positive control). To obtain dead cells, bacterial cells were autoclaved at $121^{\circ} \mathrm{C}$ for $20 \mathrm{~min}$. The autoclaving process led to microbial inactivation percentages of: $\sim 100,99$, and $87 \%$ in terms of culturability, ATP and metabolic activity, respectively. Henceforth, the live cells suspension and the dead cells suspension will be called " $\mathrm{C}^{-}$" and " $\mathrm{C}^{+}$," respectively.

After biocide exposure, the cells were neutralized as described in section "Minimum Bactericidal Concentration Determination," centrifuged (4,000 rpm, $5 \mathrm{~min}$ ), washed twice (to remove biocide) and then resuspended in saline for further analysis.

To fully understand the mechanisms of antimicrobial action of the selected biocides, the following parameters were evaluated after biocide exposure, namely: (i) culturability; (ii) membrane integrity; (iii) metabolic activity; (iv) cellular energy; and (v) structural and morphological changes.

\section{Culturability}

Bacterial cells were serially diluted in saline solution and plated on plate count agar (PCA) using the drop plate method (Reed and Reed, 1948). Then, the plates were incubated at $30^{\circ} \mathrm{C}$ for 24h. Afterward, colonies were enumerated and the results expressed as logarithm of the colony forming units per milliliter (CFUs/mL). Three independent experiments were performed for each condition.

\section{Membrane Integrity}

The LIVE/DEAD ${ }^{\circledR}$ Baclight ${ }^{\mathrm{TM}}$ kit (Invitrogen) was used to assess membrane integrity of bacterial cells after exposure to biocides. In brief, an aliquot of $1 \mathrm{~mL}$ was filtered through a $0.2-\mu \mathrm{m}$ Nucleopore $^{\circledR}$ (Whatman) black polycarbonate membrane and stained with $250 \mu \mathrm{l}$ of SYTO9TM and $50 \mu$ l of propidium iodide (PI) in the dark (Barros et al., 2021). After reacting for $7 \mathrm{~min}$, the stains were filtered and the samples mounted on a slide with immersion oil. Then, samples were observed using a 100x objective oil immersion fluorescence objective of a LEICA DMLB2 microscope incorporated with a mercury lamp HBO/100W/3 and a CCD camera. The optical filters used were a combination of a $480-500 \mathrm{~nm}$ excitation filter and a $485 \mathrm{~nm}$ emission filter (Chroma 61000-V2 DAPI/FITC/TRITC; Ferreira et al., 2011). A IM50 software (LEICA) was used to record images. At least 15 images were captured for each sample and the experiments were repeated in three different occasions.

\section{Metabolic Activity}

Stock solutions of resazurin $(400 \mu \mathrm{M})$ were prepared in sterile ultrapure water and stored at $-20^{\circ} \mathrm{C}$. In brief, $190 \mu \mathrm{l}$ of samples and $10 \mu \mathrm{l}$ of resazurin were added in the dark to each well. Then, the fluorescence was recorded at $\lambda$ excitation $=570 \mathrm{~nm}$ and $\lambda$ emission $=590 \mathrm{~nm}$ every $30 \mathrm{~min}$ for $24 \mathrm{~h}$ using a FLUOstar ${ }^{\circledR}$ Omega microtiter plater reader (BMG LABTECH, Germany). Blank assay was performed using saline solution. The results were presented in terms of relative fluorescence units (RFU). Three independent experiments with triplicates were performed for each case.

\section{Cellular Energy (ATP)}

Adenosine triphosphate was measured using BacTiter-Glo ${ }^{\mathrm{TM}}$ Microbial Cell Viability Assay (Promega, Madison, Wisconsin, United States) according to the manufacturer's instructions. 
Briefly, $100 \mu \mathrm{l}$ of samples was mixed with $100 \mu \mathrm{l}$ of BacTiter-Glo ${ }^{\mathrm{TM}}$ reagent in white 96-well plates and allowed to interact for $5 \mathrm{~min}$ at room temperature. Then, luminescence was recorded using the lens from a FLUOstar ${ }^{\circledR}$ Omega microtiter plater reader (BMG LABTECH, Germany) and the output values were recorded in relative light units (RLU). Background luminescence was removed by recording luminescence of control wells without cells. Three independent experiments with triplicates were performed for each case.

\section{Transmission Electron Microscopy Analysis}

For the ultrastructure analysis, cells were fixed in a solution of 2\% glutaraldehyde (\#16316; Electron Microscopy sciences) with 2.5\% formaldehyde (\#15713; Electron Microscopy sciences) in $0.1 \mathrm{M}$ sodium cacodylate buffer $(\mathrm{pH} 7.4)$ for $24 \mathrm{~h}$, at room temperature, and post fixed in $2 \%$ osmium tetroxide (\#19190; Electron Microscopy Sciences) diluted in $0.1 \mathrm{M}$ sodium cacodylate buffer. After centrifugation, the pellet was resuspended in Histogel $^{\mathrm{TM}}$ (Thermo, HG-4000-012) and then stained with aqueous $1 \%$ uranyl acetated solution overnight, dehydrated and embedded in Embed-812 resin (\#14120; Electron Microscopy sciences). Ultra-thin sections ( $50 \mathrm{~nm}$ thickness) were cut on a RMC Ultramicrotome (PowerTome, United States) using Diatome diamond knifes, mounted on mesh copper grids (Electron Microscopy Sciences), and stained with uranyl acetate substitute (\#11000; Electron Microscopy Sciences) and lead citrate (\#11300; Electron Microscopy Sciences) for $5 \mathrm{~min}$ each. Samples were viewed on a JEOL JEM 1400 transmission electron microscope (JEOL, Tokyo, Japan) and images were digitally recorded using a CCD digital camera Orius 1100W (Tokyo, Japan). The transmission electronic microscopy (TEM) was performed at the HEMS core facility at i3S, University of Porto, Portugal with the assistance of Ana Rita Malheiro and Rui Fernandes.

\section{Statistical Analysis}

Statistical analysis was performed using Graphpad Prism version 9.0.1 for macOS software (GraphPad Software, San Diego, CA, United States). Data was analyzed using one-way ANOVA with Tukey's multiple comparison test. A confidence level of $95 \%$ $(p<0.05)$ was used as statistical significance. All data was expressed as means $\pm \mathrm{SD}$ of three independent experiments.

\section{RESULTS AND DISCUSSION}

\section{Minimum Bactericidal Concentration}

The antimicrobial activity of BAC and DBNPA was tested and the resulting time-kill curves are presented in Figure 1. As can be observed from Figure 1, both biocides were able to completely inactivate bacterial cells in less than $1 \mathrm{~h}$ of contact time.

Figure 1A shows that the exposure of $P$. fluorescens to BAC at 25,35 , and $40 \mathrm{mg} / \mathrm{L}$, did not affect the number of culturable cells $(p>0.05)$. On the other hand, at $60 \mathrm{~min}$ of contact time, a 1.3 and $1.8-\log _{10}$ reduction was observed for 60 and $80 \mathrm{mg} / \mathrm{L}$, respectively.

As antimicrobial activity of biocides is dose and timedependent (Grobe et al., 2002; Fernandes et al., 2020) the

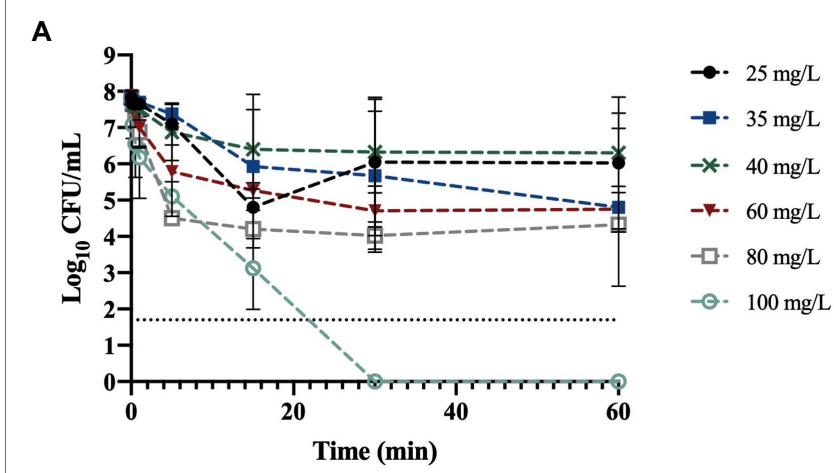

B

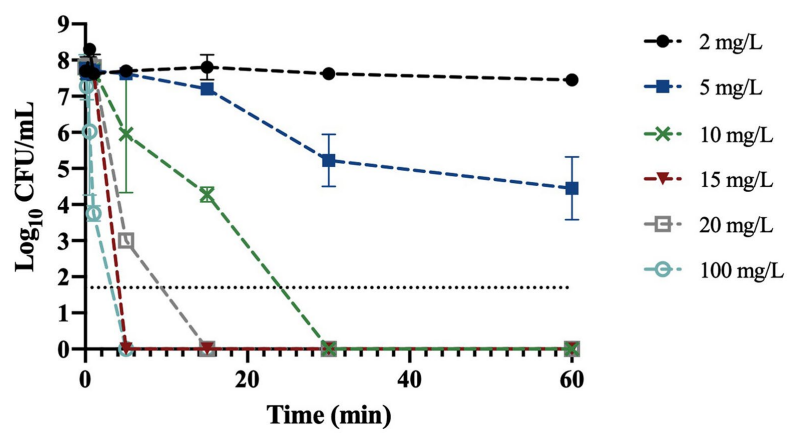

FIGURE 1 | Logarithm of the colony forming unit per milliliter (CFU/mL) of planktonic Pseudomonas fluorescens exposed to: (A) benzalkonium chloride (BAC) and (B) dibromonitrilopropionamide (DBNPA) at different concentrations along time. The line indicates the method detection limit $\left(1.70 \log _{10} \mathrm{CFU} / \mathrm{mL}\right)$. The means \pm SD of three independent experiments are illustrated.

MBC was determined. The MBC corresponds to the lowest concentration of biocide that is able to kill $99.9 \%$ of the initial bacterial cells (Parvekar et al., 2020). The only concentration able to reduce culturability to zero (6.3- $\log _{10}$ reduction) was $100 \mathrm{mg} / \mathrm{L}$, so this concentration was assumed to be the MBC for BAC. Fazlara and Ekhtelat (2012) obtained an MBC of $80 \mathrm{mg} / \mathrm{L}$ for Pseudomonas aeruginosa, which is lower than the value obtained in the present study; although, their bacterial concentration was also lower $\left(10^{6} \mathrm{CFU} / \mathrm{mL}\right)$. On the other hand, Ko et al. (2007) obtained a MBC of $16 \mathrm{mg} / \mathrm{L}$ for both $P$. aeruginosa and Pseudomonas putida in bold medium, which is six times lower than the value obtained in this study (although the initial bacterial load was not specified). Additionally, in the same study, the MBC determination in a different culture medium (Mueller-Hinton Broth) resulted in different $\mathrm{MBC}$ values, namely, 63 and $32 \mathrm{mg} / \mathrm{L}$ for both $P$. aeruginosa and $P$. putida, respectively.

Regarding Figure 1B, it is noticeable that DBNPA at $2 \mathrm{mg} / \mathrm{L}$ did not affect the culturability of bacterial cells, even after $1 \mathrm{~h}$ of contact time. The exposure of $P$. fluorescens cells to $5 \mathrm{mg} / \mathrm{L}$ of DBNPA resulted in a 0.3 and $1.3-\log _{10}$ reduction $(p<0.05)$ after 30 and $60 \mathrm{~min}$ of contact time, respectively. Exposing the cells to $10 \mathrm{mg} / \mathrm{L}$ led to an $6.3-\log _{10}$ reduction of bacterial culturability within $30 \mathrm{~min}$. Therefore, the MBC of DBNPA was found to be $10 \mathrm{mg} / \mathrm{L}$. The differences observed between 
the concentrations of either 2 or $5 \mathrm{mg} / \mathrm{L}$ and all the other concentrations were statistically significant $(p<0.05)$. Russo (2016) found that the MBC of DBNPA against Escherichia coli in Mueller-Hinton Broth after $24 \mathrm{~h}$ of exposure was $20 \mathrm{mg} / \mathrm{L}$. In the study of Ko et al. (2007), the MBC of DBNPA was 128 and $8 \mathrm{mg} / \mathrm{L}$ for $P$. putida and $P$. aeruginosa, respectively.

The differences observed in the MBC values for both biocides show that the MBC is dependent on the microorganism species/ strain, the culture medium, and the method used to evaluate it (Bridier et al., 2011).

\section{Mechanisms of Antimicrobial Action of Biocides}

In order to understand the mechanisms of antimicrobial action of BAC and DBNPA, bacterial cells were exposed to biocides for $30 \mathrm{~min}$, at four different biocidal concentrations. The choice of a $30 \mathrm{~min}$ contact time follows the discussion undertaken about the $\mathrm{MBC}$ and the minimum time to achieve non-culturability for both biocides. The biocidal concentrations were chosen to meet the $\mathrm{MBC}$, two concentrations below the $\mathrm{MBC}$ and one concentration above it. After the exposure to the selected biocides several parameters were analyzed, namely: culturability, membrane integrity, metabolic activity, cell energy, and cell morphology. For interpretation and comparison purposes, these parameters were also assessed for the controls: negative control $\left(\mathrm{C}^{-}\right)$corresponding to live cells of $P$. fluorescens and the positive control $\left(\mathrm{C}^{+}\right)$from the autoclaved cells (dead cells).

\section{Effect of Biocides on Culturability}

The culturability of cells previously exposed to BAC and DBNPA was evaluated and the results are presented in Figure 2.

The results illustrated in Figure $\mathbf{2}$ show that total inactivation (no CFU counts) of bacterial cells was obtained for: (i) 100 and $160 \mathrm{mg} / \mathrm{L}$ of BAC; (ii) 10 and $35 \mathrm{mg} / \mathrm{L}$ of DBNPA; and (iii) autoclaved cells $\left(\mathrm{C}^{+}\right)$. These results are not surprising as these concentrations correspond to the MBC's and concentrations above the MBC (Figure 1) or, in the case of $\mathrm{C}^{+}$, to the positive control (dead cells).

Figure 2A also shows that the lowest BAC concentrations tested, 30 and $40 \mathrm{mg} / \mathrm{L}$, affected the culturability of cells as they resulted in a 0.3 and $1.3 \log _{10}$-reduction, respectively. Similarly, the lowest DBNPA concentrations (5 and $8 \mathrm{mg} / \mathrm{L}$ ) also reduced the culturability in 0.2 and $1.3 \log _{10}$, respectively.

\section{Effect of Biocides on Membrane Integrity}

The membrane integrity was evaluated using two different dyes: SYTO 9 and PI. PI is only able to penetrate cells with damaged membranes; it binds to nucleic acids and emits a red fluorescent light. SYTO9, which also binds to nucleic acids, is used as a viability marker as it enters all cells, regardless their membrane integrity, staining cells green (Ding et al., 2017).

Figure 3A shows an increase of PI-stained cells with increasing BAC concentrations. The positive control presented 79 and $21 \%$ of SYTO9 and PI-stained cells, respectively. On the other hand, total loss of membrane integrity (100\% PI uptake) was observed for the concentrations equal to or above $30 \mathrm{mg} / \mathrm{L}$,
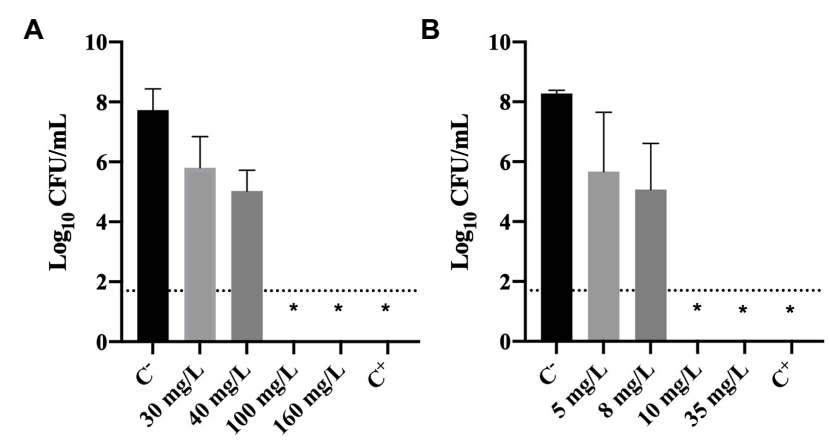

FIGURE 2 | Logarithm of the CFU/mL of Pseudomonas fluorescens cells after being exposed for $30 \mathrm{~min}$ to different concentrations of (A) BAC and (B) DBNPA. Controls were performed with only live cells $\left(\mathrm{C}^{-}\right)$ and dead cells, killed by autoclave $\left(\mathrm{C}^{+}\right)$. The means $\pm \mathrm{SD}$ of three independent experiments are presented. The line indicates the method detection limit $\left(1.70 \log _{10} \mathrm{CFU} / \mathrm{mL}\right)$. The symbol * means that no CFUs were detected.

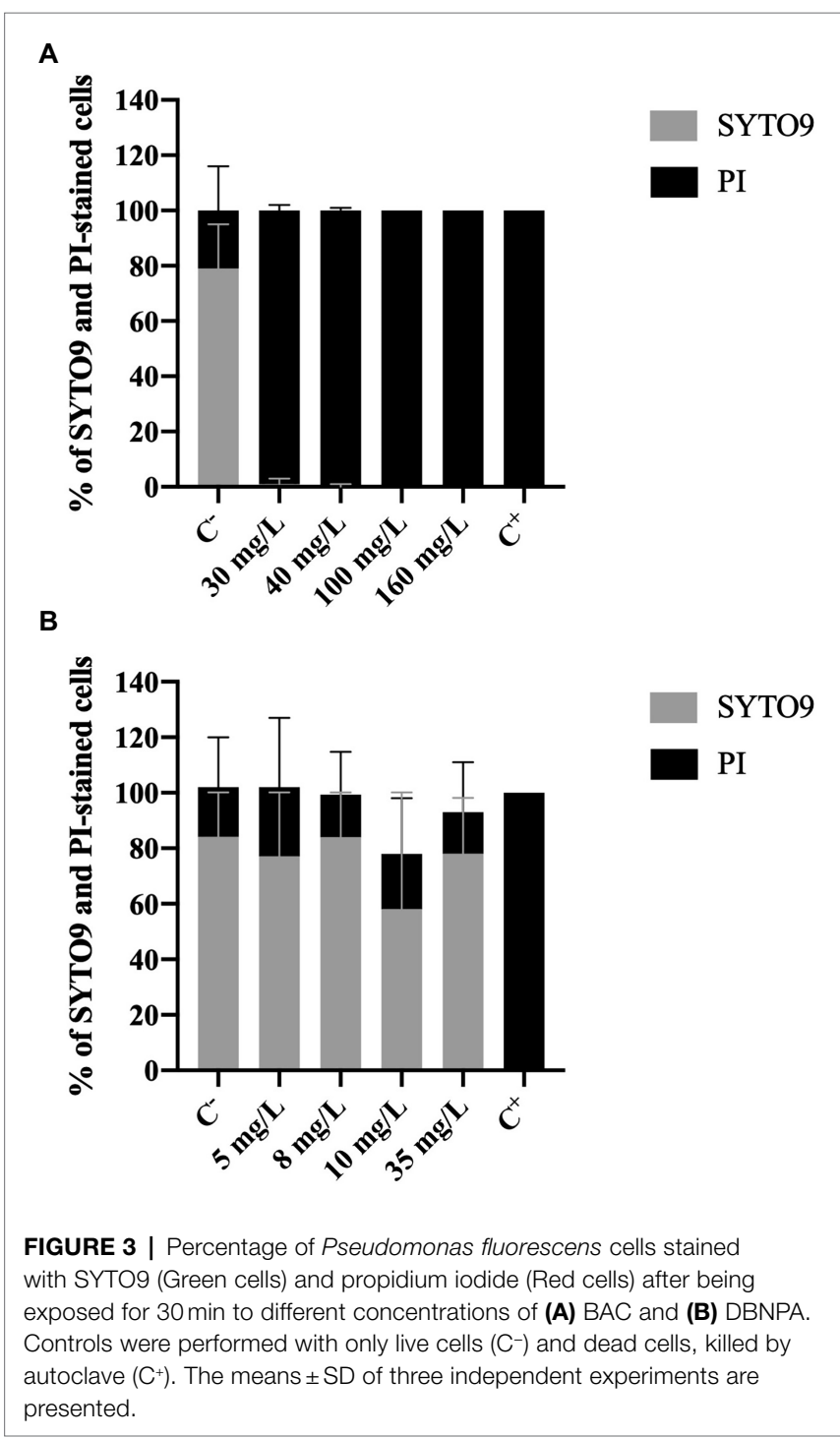


as well as for the negative control $(p<0.0001)$. Fernandes et al. (2020) also studied the membrane integrity of $P$. fluorescens after being exposed to BAC (10 and $100 \mathrm{mg} / \mathrm{L})$ and found similar values of PI uptake percentage (84-100\%).

On the other hand, no statistical differences $(p>0.05)$ were observed in the PI and the SYTO9 uptake between $\mathrm{C}^{-}$and DBNPA-exposed cells (Figure 3B). These PI uptake values (25, 15,20 , and $15 \%$, respectively for $5,8,10$, and $35 \mathrm{mg} / \mathrm{L}$ ) are also similar to the ones observed in the negative control $\left(\mathrm{C}^{-}\right)$. Since the $\mathrm{C}^{-}$corresponds to live cells in the growth phase, these results suggest that the DBNPA did not have a significant impact on the membrane integrity of $P$. fluorescens. Additionally, and as expected, the autoclaved cells $\left(\mathrm{C}^{+}\right)$showed total loss of membrane integrity (100\% PI uptake).

It is important to note that the PI uptake percentages observed for $\mathrm{C}^{-}(18-21 \%)$ are consistent with data reported in the literature (Fernandes et al., 2020; Barros et al., 2021). The question why live cells can be stained with PI remains unanswered (Shi et al., 2007). Some authors (Shi et al., 2007) showed that active growing cells can have, for short periods of time, their membrane's integrity affected. Other studies (Kirchhoff and Cypionka, 2017) attributed the PI uptake by intact live cells to the existence of a high membrane potential.

In short, results from Live/Dead assay clearly demonstrate that the two tested biocides have a different impact at the cells membrane level: BAC disrupts cells membranes, while DBNPA does not affect the cells membrane integrity (independently of inactivating the cells, or not). The interpretation of these results will be further developed in sub-section "The Issue of Viable but Non-culturable Cells," when addressing the issue of viable but not culturable cells.

\section{Effect of Biocides on Metabolic Activity}

Metabolic activity of cells was determined using the resazurin dye assay. Resazurin is commonly used to assess bacterial viability. Basically, resazurin is a weakly-fluorescent dye that is reduced to a pink highly-fluorescent dye (resorufin). This reduction only occurs in the presence of metabolically active cells (Bueno et al., 2002; Csepregi et al., 2018). Therefore, the intensity of fluorescence can be correlated to the presence of metabolically active cells (viable cells).

The results obtained for resazurin assays (in RFU units) are presented in Figure 4.

Figure 4A, shows that BAC has a significant effect $(p<0.0001)$ on the reduction of cells' metabolic activity as compared with the negative control $\left(\mathrm{C}^{-}\right)$. More specifically, a $60-80 \%$ decrease in fluorescence intensity can be observed between BAC-exposed cells (for all tested concentrations) and the live ones from $\mathrm{C}^{-}$. Although the impact on cells' metabolic activity is noticeable for concentrations below the MBC $(100 \mathrm{mg} / \mathrm{L}), 160 \mathrm{mg} / \mathrm{L}$ was the only concentration presenting similar values to the autoclaved cells $\left(\mathrm{C}^{+} ; p>0.05\right)$. These results suggest that the $\mathrm{MBC}$ concentration is not enough to decrease the cells metabolic activity to the levels observed in autoclaved cells.

Similarly, cells exposed to increasing DBNPA concentrations (Figure 4B) significantly decreased $(p<0.0001)$ the fluorescence intensity when comparing to $\mathrm{C}^{-}$. These results indicate that DBNPA affected the metabolic activity of cells (reductions between 58 and 78\%), although without causing membrane damage. Also, the differences between $\mathrm{C}^{+}$and the DBNPA concentrations tested were statistically significant, except for $35 \mathrm{mg} / \mathrm{L}(p>0.05)$. Again, only the concentration above the MBC seems to be able to decrease the cells' metabolic activity to levels comparable with the ones observed for the autoclaved (dead) cells.

\section{Effect of Biocides on Cell Energy}

Adenosine triphosphate bioluminescence assay is a powerful tool to assess cell viability (Lomakina et al., 2015). ATP is a key carrier of energy in cells, it is essential for cell respiration
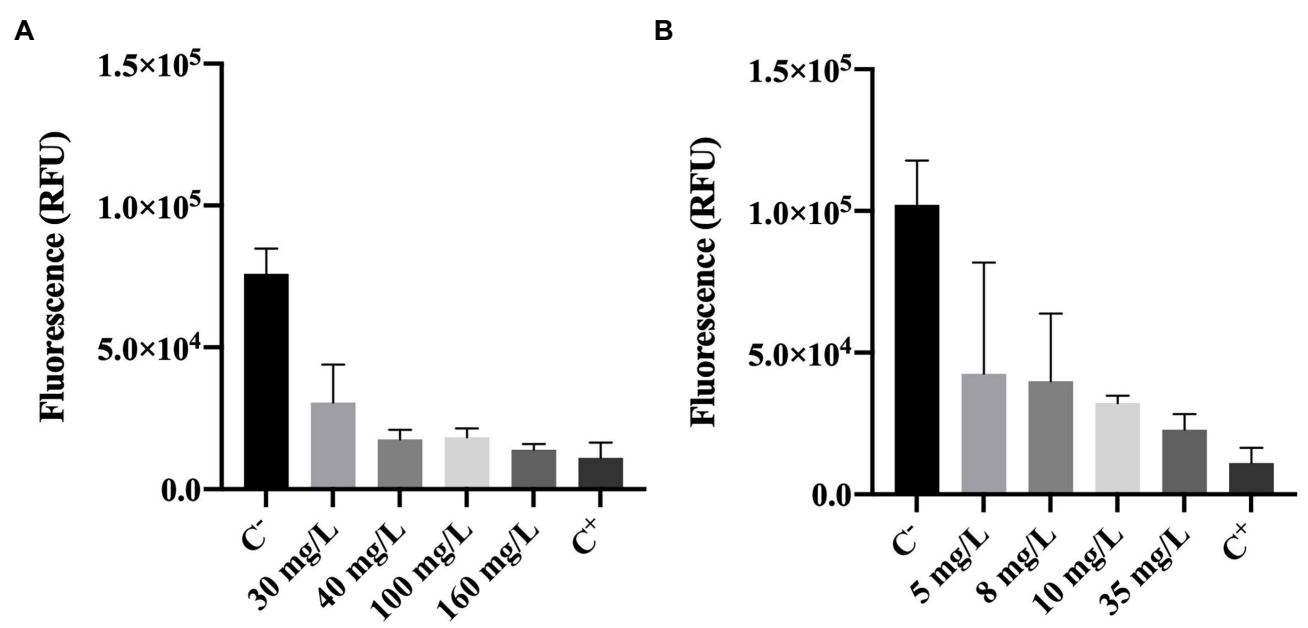

FIGURE 4 | Fluorescence of Pseudomonas fluorescens cells stained with resazurin after being exposed for 30 min to different concentrations of (A) BAC and (B) DBNPA. Controls were performed with only live cells $\left(\mathrm{C}^{-}\right)$and dead cells, killed by autoclave $\left(\mathrm{C}^{+}\right)$. The means $\pm \mathrm{SD}$ of three independent experiments with triplicates are presented (RFU, relative fluorescence units). 
and its synthesis is immediately stopped after cell death (Lomakina et al., 2015). The ATP kit has a reagent that lyses cells. The principle of the method is that when cells are lysed ATP is released and the oxidation of luciferin (an organic substrate) by luciferase (an enzyme) uses ATP from viable cells to produce light. So, a higher luminescence (RLU) signal can be correlated to the presence of higher levels of ATP and, therefore, a higher number of viable cells (Lomakina et al., 2015; Kumar and Ghosh, 2019). As described in the methodology section, cells are lysed upon contact with one of the reagents present in the ATP test kit, enabling the detection of ATP. It is important to highlight that the ATP measured in this work (results shown in Figure 5) is the intracellular ATP (ATP present inside living cells), since upon biocide exposure, the samples were centrifuged and the supernatant discarded.

The luminescence results presented in Figure 5A show that increasing BAC significantly decreased the measured luminescence when compared to the positive control $(p<0.0001)$, suggesting a decrease on the ATP levels. Although from Figure 1A it was observed that $40 \mathrm{mg} / \mathrm{L}$ of BAC was far below the $\mathrm{MBC}$ (which was found to be $100 \mathrm{mg} / \mathrm{L}$ ), the differences between $40,100,160 \mathrm{mg} / \mathrm{L}$ and $\mathrm{C}^{-}$were not statistically significant $(p>0.05)$. These results seem to indicate that BAC concentrations equal to or above $40 \mathrm{mg} / \mathrm{L}$ decrease the ATP to levels similar to the ones from autoclaved dead cells $\left(\mathrm{C}^{+}\right)$. In the work of Aragones et al. (2012), when P. aeruginosa was tested with $100 \mathrm{mg} / \mathrm{L}$ of BAC for $5 \mathrm{~min}$ of contact time, a $0.3 \log _{10}$-reduction of luminescence was observed. Although this value is low compared to the $1.9 \log _{10}$-reduction obtained in the present study, the contact time used was also lower and the microorganism (a Gram-negative) was not from the same species.

The comparison between Figure 5A (BAC) and Figure 5B (DBNPA) seems to indicate a smoother decreasing tendency between DBNPA concentration and luminescence decrease (Figure 5B) as compared to BAC, which can be related to the lytic action of BAC that leads to the release of intracellular contents (including ATP). Although luminescence decreases with increasing DBNPA concentrations (Figure 5B), there is a statistically difference $(p<0.0001)$ among all the tested concentrations and both controls $\left(\mathrm{C}^{+}\right.$and $\left.\mathrm{C}^{-}\right)$. The only exception is observed between the $35 \mathrm{mg} / \mathrm{L}$ and $\mathrm{C}^{+}$, which did not present statistically significant differences $(p>0.05)$. These results suggest that a $35 \mathrm{mg} / \mathrm{L}$ concentration of DBNPA is needed to decrease ATP to levels similar to the ones observed in cells submitted to an autoclaving process $\left(\mathrm{C}^{+}\right)$.

\section{Effect of Biocides on Cell Structure and Morphology}

In this work, TEM was used to accurately visualize biocide impact on bacterial cell envelope. For this study, we examined both controls $\left(\mathrm{C}^{+}\right.$and $\left.\mathrm{C}^{-}\right)$and the cells previously exposed to BAC and DBNPA at the MBCs (100 and $10 \mathrm{mg} / \mathrm{L}$, respectively; Figure 6).

Figures $6 \mathrm{~A}, \mathrm{~B}$ revealed that untreated bacteria $\left(\mathrm{C}^{-}\right)$have a dense cytosol and a well-defined and intact bacterial cell envelope.

From Figures 6C,D is possible to notice the appearance of many vacuoles (islands of cytoplasm) that are not present in the $\mathrm{C}^{-}$. In a recent study, Ziklo et al. (2021) observed the same islands of cytoplasm on P. aeruginosa cells after dodecyldimethyl-ammonium chloride (a QAC compound) treatment. Also, BAC exposure led to a loss in intracellular content, with genetic material spread across the cytoplasm. Although there is no clear evidence of membrane disruption, the leaflets of bacterial cell envelope cannot be distinguished. The same trend has already been observed for colistin (Nguyen et al., 2021) and Polymyxin B (Voget et al., 2015), two antimicrobials which also target the outer membrane.

The exposure of cells to DBNPA (Figures 6E,F) appeared to have no effect on the bacterial cell envelope, but resulted in the loss of cellular components, which can be observed by the appearance of translucent zones.

Autoclaved cells $\left(\mathrm{C}^{+}\right)$Figures 6G,H-exhibited a high decrease in intracellular electron density. Besides, a lot of vesicles can
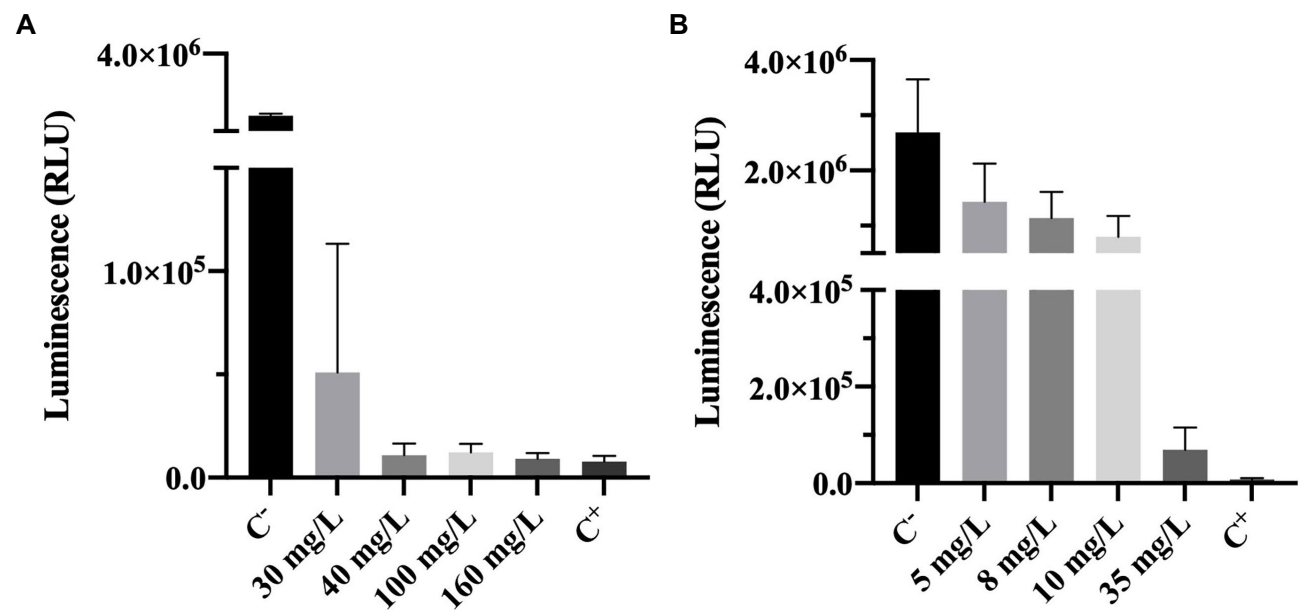

FIGURE 5 | Luminescence of Pseudomonas fluorescens cells after being exposed for 30 min to different concentrations of (A) BAC and (B) DBNPA. Controls were performed with only live cells $\left(\mathrm{C}^{-}\right)$and dead cells, killed by autoclave $\left(\mathrm{C}^{+}\right)$. The means $\pm \mathrm{SD}$ of three independent experiments with triplicates are presented (RLU, relative light units). 

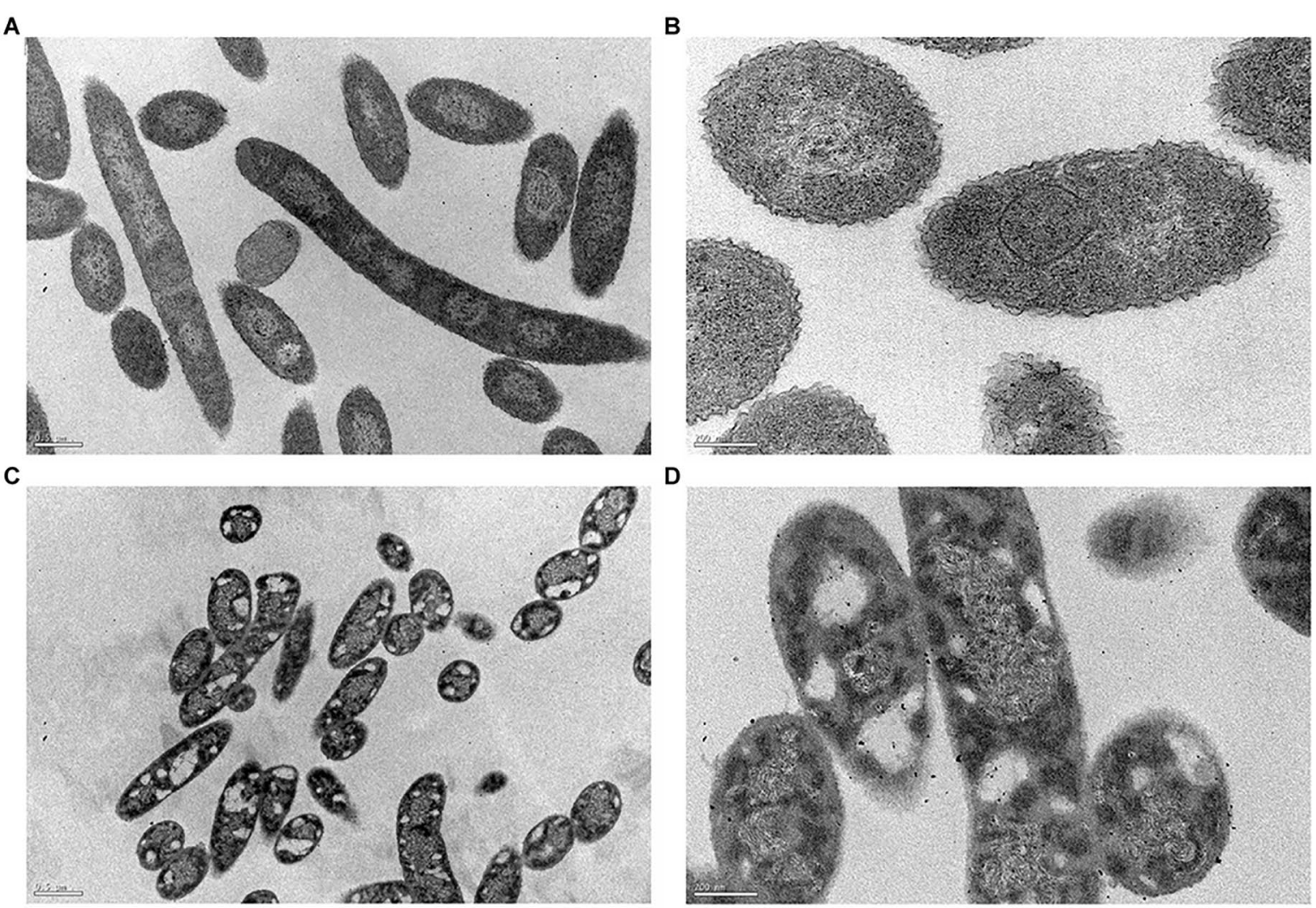

E

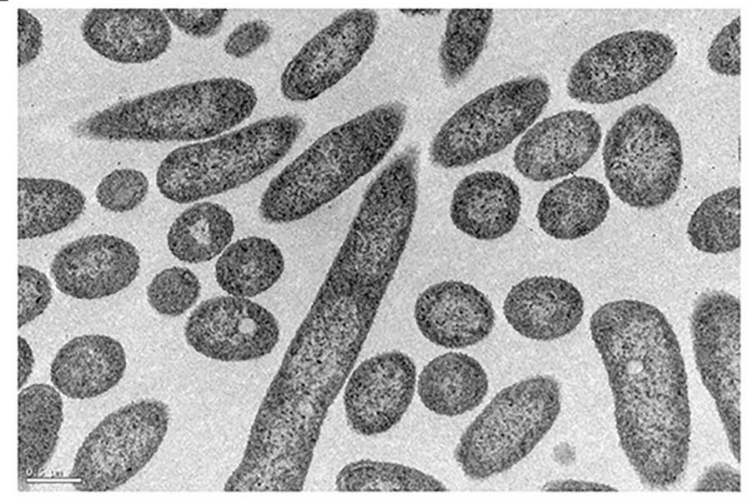

$\mathbf{F}$

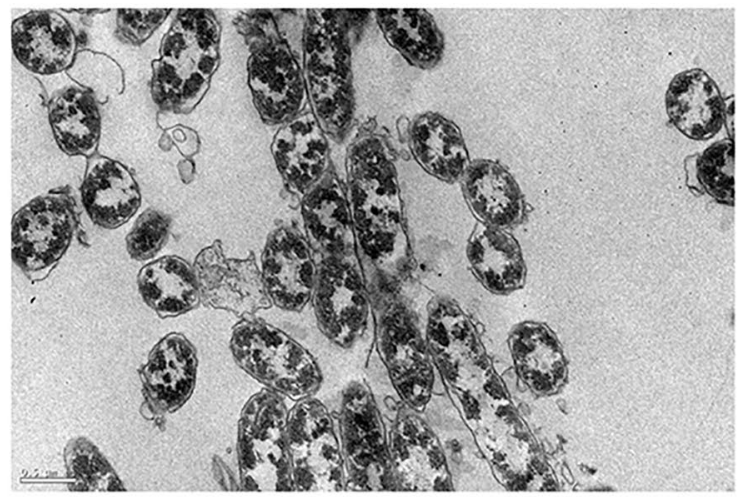

G

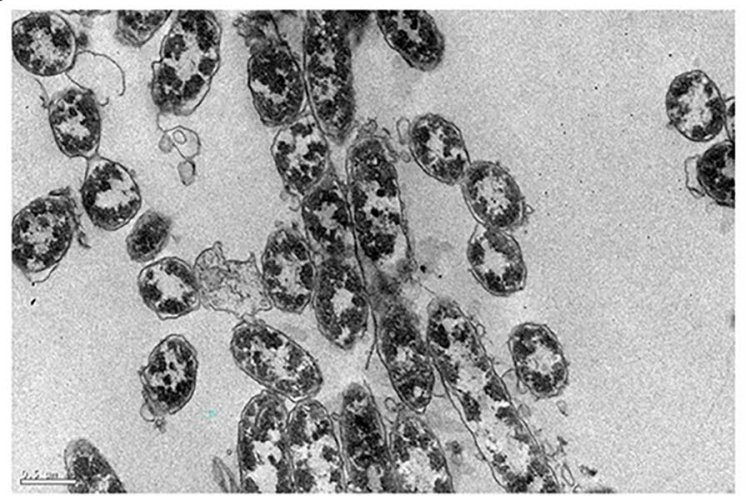

H

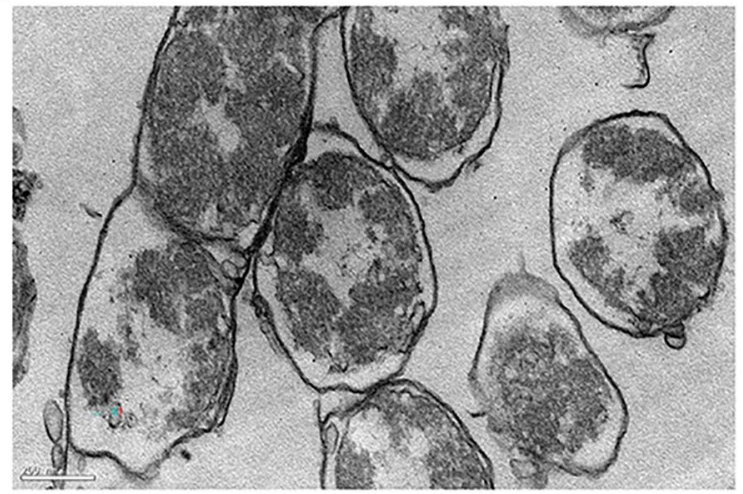

FIGURE 6 | Transmission electron micrographs of Pseudomonas fluorescens cells: (A,B) untreated-C-; (C,D) exposed for 30 min to BAC minimum bactericidal concentration (MBC; $100 \mathrm{mg} / \mathrm{L}) ;(\mathbf{E}, \mathbf{F})$ exposed to DBNPA MBC (10 mg/L); and $\mathbf{( G , H )}$ after an autoclaving process-- $\mathrm{C}^{+}$. Images $(\mathbf{A}, \mathbf{C}, \mathbf{E}, \mathbf{G})$ are under a lower magnification $(25,000 \times)$, while images (B,D,F,H) are at a higher magnification $(80,000 \times)$. 
be observed. Although the different layers of membrane structure cannot be distinguished, a massive cell wall damage was observed.

In short, all treatments induced structural and morphological changes to $P$. fluorescens and TEM images are in agreement with the results from the preceding analysis.

\section{Mechanistic Insights Into the Antimicrobial Action of BAC and DBNPA}

The present work compares the antimicrobial effects of BAC and DBNPA and addresses the question "how far are injured cells from their dead state?". This discussion is held for all the evaluated parameters (culturability, membrane integrity, metabolic activity, ATP, and TEM). The findings discussed so far, are summarized in Table 1.

The most relevant observation that steps out from the results is the interaction of the two tested biocides with the cell's membrane: while BAC clearly affects membrane integrity, DBNPA shows similar PI/SYTO9 uptake levels (no membrane damage) for all tested concentrations. However, both biocides, in higher or lower extent, interfered with the other evaluated parameters. These results will be discussed in the next paragraphs in light of the mechanisms of action proposed in the literature.

Due to its cationic nature, BAC is known to bind electrostatically with the oppositely charged cell wall (Simões et al., 2005), followed by a sequence of events that include: (i) reaction with the cytoplasmatic membrane, leading to its disintegration; (ii) the intracellular constituents start to leak, followed by nucleic acids and proteins degradation; and (iii) autolytic enzymes lyse the cell wall (Salton, 1968; McDonnell, 2007; Gerba, 2015; see

TABLE 1 | Summary of results obtained using different techniques to study the mechanisms of action of BAC and DBNPA.

\begin{tabular}{|c|c|c|c|}
\hline \multirow{3}{*}{$\begin{array}{l}\text { Functional } \\
\text { interpretation }\end{array}$} & \multirow[t]{3}{*}{ Method } & \multicolumn{2}{|c|}{ Findings } \\
\hline & & BAC & DBNPA \\
\hline & & $\begin{array}{l}\text { Tested concentrations: } \\
30,40,100(\mathrm{MBC}) \text {, and } \\
160 \mathrm{mg} / \mathrm{L}\end{array}$ & $\begin{array}{l}\text { Tested } \\
\text { concentrations: } 5,8 \text {, } \\
10(\mathrm{MBC}) \text {, and } \\
35 \mathrm{mg} / \mathrm{L}\end{array}$ \\
\hline Culturability & Drop plate & $\begin{array}{l}\text { Non-culturable cells (for } \\
\text { concentrations equal or } \\
\text { above the MBC) }\end{array}$ & $\begin{array}{l}\text { Non-culturable cells } \\
\text { (for concentrations } \\
\text { equal or above the } \\
\text { MBC) }\end{array}$ \\
\hline $\begin{array}{l}\text { Membrane } \\
\text { integrity }\end{array}$ & $\begin{array}{l}\text { PI+SYTO9 } \\
\text { staining } \\
\text { (BacLight) }\end{array}$ & $\begin{array}{l}\text { Highly affected (even for } \\
\text { concentrations lower } \\
\text { than } \mathrm{MBC} \text { ) }\end{array}$ & $\begin{array}{l}\text { Not affected (even for } \\
\text { concentrations higher } \\
\text { than MBC) }\end{array}$ \\
\hline $\begin{array}{l}\text { Metabolic } \\
\text { activity }\end{array}$ & Resazurin & $\begin{array}{l}\text { Highly reduced (only } \\
\text { higher concentration are } \\
\text { comparable to } \\
\text { autoclaved dead cells) }\end{array}$ & $\begin{array}{l}\text { Highly reduced (only } \\
\text { higher concentration } \\
\text { are comparable to } \\
\text { autoclaved dead cells) }\end{array}$ \\
\hline ATP & $\begin{array}{l}\text { ATP } \\
\text { Promega }\end{array}$ & $\begin{array}{l}\text { Highly reduced (ATP } \\
\text { decreased to levels } \\
\text { similar to autoclaved } \\
\text { dead cells - even for } \\
\text { concentrations below } \\
\text { MBC) }\end{array}$ & $\begin{array}{l}\text { Reduced (only the } \\
\text { concentration above } \\
\text { MBC showed ATP } \\
\text { levels comparable with } \\
\text { autoclaved dead cells) }\end{array}$ \\
\hline $\begin{array}{l}\text { Structure and } \\
\text { morphology }\end{array}$ & TEM & $\begin{array}{l}\text { Vacuoles formation and } \\
\text { loss of intracellular } \\
\text { content }\end{array}$ & $\begin{array}{l}\text { Intact membranes and } \\
\text { loss of intracellular } \\
\text { content }\end{array}$ \\
\hline
\end{tabular}

Figures 6A-D). As previously discussed, the interaction between $\mathrm{BAC}$ and the cell's membrane is so strong that low BAC concentrations (below $\mathrm{MBC}$ ) induce small membrane damages (pores), which are not enough to affect culturability, yet allow PI entrance, thereby providing a false indication of "compromised viability." The induction of these pores on the cytoplasmatic membrane can lead to membrane disruption and leakage of intracellular contents, such as ATP (Nan et al., 2009; Suh et al., 2016). In fact, the exposure of bacterial cells to BAC led to a reduction of ATP content between 95 and $99 \%$, as well as a decrease in the metabolic activity above $82 \%$, for all tested concentrations. Although ATP decrease is often followed by viability loss (Suh et al., 2016; Yasir et al., 2019), only the highest tested concentration (above the MBC) showed ATP levels and a decreased metabolic activity comparable to the ones in autoclaved cells, even though bacteria lost their culturability after being exposed to BAC (in concentrations equal/above the MBC). The overall results reinforce that BAC is a lytic biocide (Chapman, 2003; Amjad, 2010; Bajpai, 2015; Figure 7A), since the membrane lost integrity, the cell lost the ability to grow in culture media (culturability), and also there was a decrease in both cell respiration and metabolic activity.

On the other hand, DBNPA's mechanism of action relies on the interaction of bromine with sulfur-containing nucleophiles present inside the cells (e.g., cysteine or glutathione), leading to the inhibition of cell metabolism (Maillard, 2002; Campa et al., 2019; see Figure 7B). Such interaction between DBNPA and the components inside the cell (keeping the membrane intact) are corroborated in the present study by the membrane integrity and TEM results. When looking into culturability results, DBNPA exhibits a faster bactericidal activity than BAC, since it requires lower concentrations to achieve "total inactivation" (non-culturability) of bacterial cells for the same contact time. Furthermore, DBNPA-exposed cells showed an inhibition of cell metabolism, although in less extent than when BAC was applied. Nonetheless, similarly to BAC, DBNPAexposed cells presented ATP and metabolic activity reduction levels consistent with the ones observed for autoclaved cells $\left(\mathrm{C}^{+}\right)$only for the highest tested concentration $(35 \mathrm{mg} / \mathrm{L})$ - the one above the MBC. This finding, common to both biocides, is related to the fact that the MBC concentration is not enough to decrease cell's viability in all functional evaluated indicators (in the case of the present study: ATP and metabolic activity) and raises important issues regarding the interpretation/ conclusions of when dead cells are effectively dead. If only the mechanisms of action were taken into account, bacterial cells exposed to $10 \mathrm{mg} / \mathrm{L}$ of DBNPA would be labelled as dead. However, the comparison of these injured cells with the autoclaved cells revealed that in fact the first ones were not really dead.

The basis of this study (as most reported in literature) is MBC's determination-the lowest concentration able to decrease culturability to zero. Instead, if looking at ATP and resazurin results, other conclusions regarding the concentration to be used would be drawn. For example, relying on ATP and resazurin the indicative concentrations to apply would be: $160 \mathrm{mg} / \mathrm{L}$ (MBC from this study: $100 \mathrm{mg} / \mathrm{L}$ ) for BAC and $35 \mathrm{mg} / \mathrm{L}$ (MBC from this study: $10 \mathrm{mg} / \mathrm{L}$ ) for DBNPA. Thus, the answer to the former 

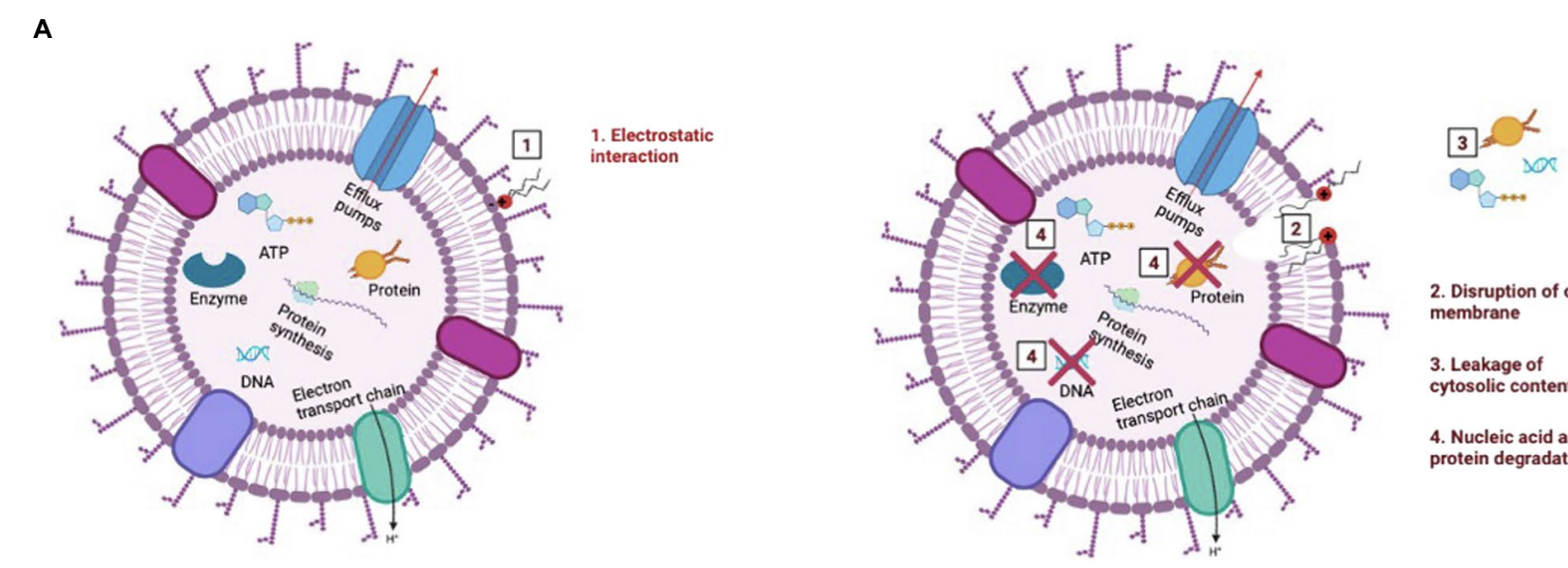

2. Disruption of cell membrane

3. Leakage of cytosolic content

4. Nucleic acid and protein degradation

B
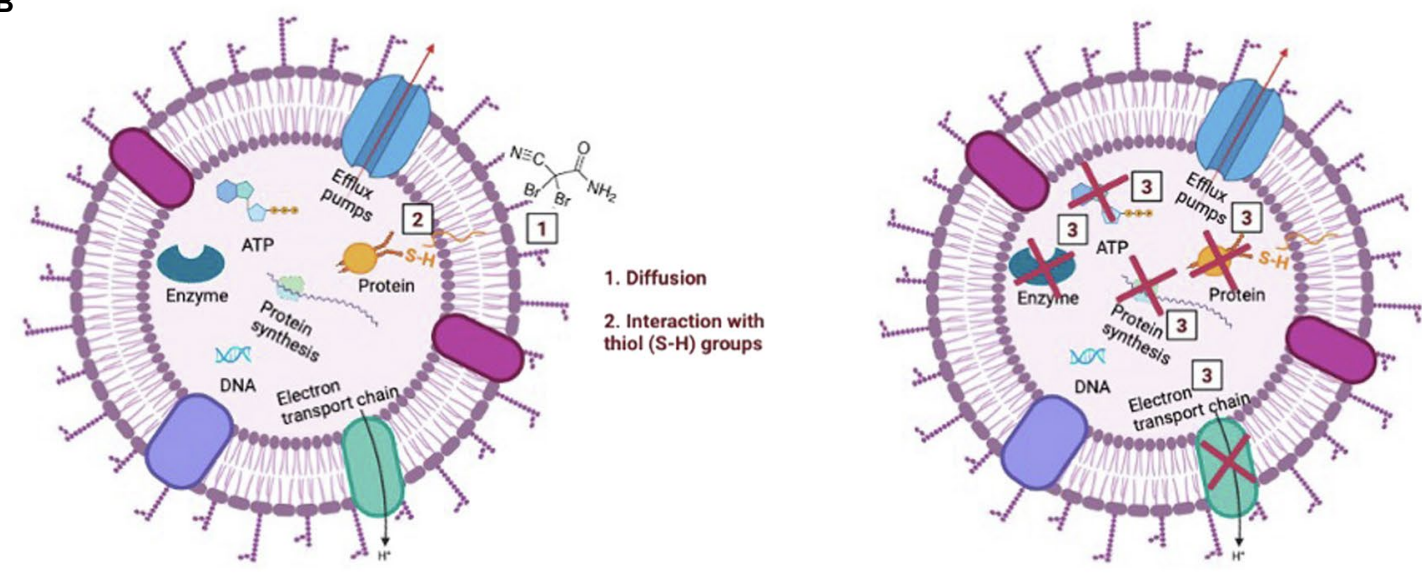

3. Irreversible damage of proteins; interrupts transport across cell membrane; and inhibits
respiration and ATP synthesis.

FIGURE 7 | Illustration of the mechanism of action of BAC (A) and DBNPA (B). These pictures were drawn based on what has been previously reported in the literature for BAC and DBNPA mechanisms of action (Salton, 1968; Maillard, 2002; McDonnell, 2007; Gerba, 2015; Campa et al., 2019).

question "how far are injured cells from its dead state?", follows the current understanding that "dead state" depends on the methodology used to evaluate it (Cangelosi and Meschke, 2014; Emerson et al., 2017). But, in the case of the present study, the inclusion of a positive control (autoclaved cells), allows us to add that the "dead state" seems to only occur for concentrations above the MBC, both for BAC and DBNPA. It is important to note that time is also a key factor when discussing antimicrobial performance of biocides, which in the case of the present study was kept constant-30 min. If higher contact times were considered, the findings herein discussed could be different.

\section{The Issue of Viable but Non-culturable Cells}

Over the past two decades, many researchers have been discussing that cells can reach the viable but non-culturable (VBNC) state as a mechanism of defense and self-preservation (Keep et al., 2006; Alam et al., 2007; Li et al., 2014; Emerson et al., 2017; Fleischmann et al., 2021; Kirschner et al., 2021). Cells enter the VBNC state when submitted to harsh stress conditions (Highmore et al., 2018; exposure to biocides/antibiotics, temperature shifts, lack of nutrients). The more usual characterization of cells that enter the VBNC state is: (i) they retain their membrane integrity; (ii) they are still metabolically active (reduced levels of metabolic activity); (iii) they are able to produce proteins; but (iv) they are not able to grow on solid media (Oliver, 2010; Ayrapetyan et al., 2014, 2018; Fleischmann et al., 2021; Kirschner et al., 2021). Also, VBNC cells are more chemically and physiologically resistant than culturable cells (Signoretto et al., 2000; Li et al., 2014), making them a major threat in many areas, including public health. If somehow the environmental conditions are restored, these cells can become culturable again. Hence, the detection of VBNC cells is important to prevent resuscitation, possible infections and adjust the biocide/antimicrobial dosing.

For illustration purposes, it could be considered that viability (for VBNC characterization) would be determined through PI/SYTO9 uptake results. Taking into consideration the mechanisms of action of the two biocides, this approach would clearly "penalize"/overestimate DBNPA in terms of VBNC calculations (Fleischmann et al., 2021), since this biocide does not interfere with the cell's membrane, during the contact time 
considered. On the other hand, VBNC cells resulting from BAC exposure could be underestimated. This issue is particularly relevant when assessing VBNC's in real-life systems, where biocides with different mechanisms of action are combinedly applied. Thus, the use of the most appropriate viability marker should be further discussed when determining VBNCs. Nonetheless, Kirschner et al. (2021) also pointed out that care must be taken when quantifying VBNC cells, especially when such quantification is based on a single viability parameter analysis. Alternatively, a double staining procedure with 4,6-di-amidino-2-phenylindole (DAPI) and tetrazolium salt 5-cyano-2,3-ditolyltetrazolium chloride (CTC) could be used to discriminate VBNC cells (Besnard et al., 2000; Fleischmann et al., 2021). Unlike PI/SYTO9, CTC does not assess membrane integrity, rather it is reduced through the electron transport chain by actively respiring bacteria (Wideman et al., 2021).

\section{CONCLUSION}

The mechanisms of action of BAC and DBNPA were discussed in the present study. BAC was confirmed to be a lytic biocide, since it disrupts the cytoplasmatic membrane and releases the intracellular cell components. Also, DBNPA, as a moderate electrophilic biocide, did not interact with the membrane, but it interfered with key components of cell's metabolism. The analysis of the results obtained by the different methods used (CFUs counting, ATP, resazurin, membrane integrity, and TEM) were in accordance to what has been previously proposed in the literature.

Furthermore, the current paper highlights an on-going discussion in the academic community regarding the need to combine different methodologies to assess cell's viability and to screen different biocidal concentrations (both below and above MBC). Furthermore, the discussion of the antimicrobial efficacy of biocides should not only consider the outputs of viability assays, but also bring into the equation the mechanism of action. Finally, the introduction of a positive control by autoclaving the cells can help to dig into the question "how far are injured cells from its dead state?"

\section{REFERENCES}

Akhova, A. V., and Tkachenko, A. G. (2014). ATP/ADP alteration as a sign of the oxidative stress development in Escherichia coli cells under antibiotic treatment. FEMS Microbiol. Lett. 353, 69-76. doi: 10.1111/15746968.12405

Alam, M., Sultana, M., Nair, G. B., Siddique, A., Hasan, N. A., Sack, R. B., et al. (2007). Viable but nonculturable Vibrio cholerae $\mathrm{O} 1$ in biofilms in the aquatic environment and their role in cholera transmission. Proc. Natl. Acad. Sci. U. S. A. 104, 17801-17806. doi: 10.1073/pnas.0705599104

Amjad, Z. (2010). The Science and Technology of Industrial Water Treatment. Boca Raton, FL: CRC Press.

Aragones, L., Escude, C., Visa, P., Salvi, L., and Mocé-Llivina, L. (2012). New insights for rapid evaluation of bactericidal activity: a semi-automated bioluminescent ATP assay. J. Appl. Microbiol. 113, 114-125. doi: 10.1111/j. 1365-2672.2012.05320.x

Ayrapetyan, M., Williams, T. C., and Oliver, J. D. (2014). Interspecific quorum sensing mediates the resuscitation of viable but nonculturable Vibrios. Appl. Environ. Microbiol. 80, 2478-2483. doi: 10.1128/AEM.00080-14

\section{DATA AVAILABILITY STATEMENT}

The raw data supporting the conclusions of this article will be made available by the authors, without undue reservation.

\section{AUTHOR CONTRIBUTIONS}

$\mathrm{LM}$ contributed to the funding acquisition. $\mathrm{LM}, \mathrm{AP}$, and $\mathrm{AB}$ conceptualized the study. $\mathrm{AB}$ performed the laboratory experiments. $\mathrm{AP}$ and $\mathrm{AB}$ contributed to writing of the original draft. LM and AP contributed to the discussion of results, review, and editing process. All authors contributed to the article and approved the submitted version.

\section{FUNDING}

This work was financially supported by: (i) LA/P/0045/2020 (ALiCE), UIDB/00511/2020 and UIDP/00511/2020 (LEPABE), funded by national funds through FCT/MCTES (PIDDAC); (ii) Project pBio4.0-Preventing Biofouling in Membrane Systems, with the reference POCI-01-0247-FEDER-033298, co-funded by the European Regional Development Fund (ERDF), through the Operational Programme for Competitiveness and Internationalization (COMPETE 2020), under the PORTUGAL 2020 Partnership Agreement; and (iii) Project PRESAGE, with the reference Aquatic/0007/2020 and ID 375 of JPI-ERANET Aquatic Pollutants, co-financed by ERA-NET Cofund Aquatic Pollutants through the FCT. AB acknowledges the award of a Ph.D. grant from FCT (SFRH/BD/146028/2019).

\section{ACKNOWLEDGMENTS}

The authors acknowledge the support of the i3S Scientific Platform HEMS, member of the national infrastructure PPBI Portuguese Platform of Bioimaging (PPBI-POCI-01-0145-FEDER022122).

Ayrapetyan, M., Williams, T., and Oliver, J. D. (2018). Relationship between the viable but nonculturable state and antibiotic persister cells. J. Bacteriol. 200, e00249-e00318. doi: 10.1128/JB.00249-18

Bajpai, P. (ed.) (2015). "The control of microbiological problems," in Pulp and Paper Industry. (Amsterdam, The Netherlands: Elsevier), 103-195.

Barros, A. C., Pereira, A., Melo, L. F., and Sousa, J. P. (2021). New functionalized macroparticles for environmentally sustainable biofilm control in water systems. Antibiotics 10:399. doi: 10.3390/antibiotics10040399

Besnard, V., Federighi, M., and Cappelier, J. (2000). Evidence of viable but nonculturable state in Listeria monocytogenes by direct viable count and CTC-DAPI double staining. Food Microbiol. 17, 697-704. doi: 10.1006/fmic.2000.0366

Bridier, A., Briandet, R., Thomas, V., and Dubois-Brissonnet, F. (2011). Comparative biocidal activity of peracetic acid, benzalkonium chloride and orthophthalaldehyde on 77 bacterial strains. J. Hosp. Infect. 78, 208-213. doi: 10.1016/j.jhin.2011.03.014

Bueno, C., Villegas, M., Bertolotti, S., Previtali, C., Neumann, M., and Encinas, A. V. (2002). The excited-state interaction of resazurin and resorufin with aminesin aqueous solutions. Photophysics and photochemical reaction. Photochem. Photobiol. 76, 385-390. doi: 10.1562/0031-8655(2002)076<0385:te sior $>2.0 . \mathrm{co} ; 2$ 
Campa, M. F., Techtmann, S. M., Ladd, M. P., Yan, J., Patterson, M., Amaral, A. G. M., et al. (2019). Surface water microbial community response to the biocide 2, 2-dibromo-3-nitrilopropionamide, used in unconventional oil and gas extraction. Appl. Environ. Microbiol. 85, e01336-e01419. doi: 10.1128/ AEM.01336-19

Cangelosi, G. A., and Meschke, J. S. (2014). Dead or alive: molecular assessment of microbial viability. Appl. Environ. Microbiol. 80, 5884-5891. doi: 10.1128/ AEM.01763-14

Chapman, J. S. (2003). Biocide resistance mechanisms. Int. Biodeterior. Biodegrad. 51, 133-138. doi: 10.1016/S0964-8305(02)00097-5

Csepregi, R., Lemli, B., Kunsági-Máté, S., Szente, L., Kőszegi, T., Németi, B., et al. (2018). Complex formation of resorufin and resazurin with B-cyclodextrins: can cyclodextrins interfere with a resazurin cell viability assay? Molecules 23:382. doi: 10.3390/molecules23020382

Denyer, S. P. (1990). Mechanisms of action of biocides. Int. Biodeterior. 26, 89-100. doi: 10.1016/0265-3036(90)90050-H

Ding, T., Suo, Y., Xiang, Q., Zhao, X., Chen, S., Ye, X., et al. (2017). Significance of viable but nonculturable Escherichia coli: induction, detection, and control. J. Microbiol. Biotechnol. 27, 417-428. doi: 10.4014/jmb.1609.09063

Emerson, J. B., Adams, R. I., Román, C. M. B., Brooks, B., Coil, D. A., Dahlhausen, K., et al. (2017). Schrödinger's microbes: Tools for distinguishing the living from the dead in microbial ecosystems. Microbiome 5:86. doi: 10.1186/s40168-017-0285-3

European Committee Standardisation (2010). "European Standard EN 1276: 2009/AC: 2010. Chemical Disinfectants and Antiseptics-Quantitative Suspension Test for the Evaluation of Bactericidal Activity of Chemical Disinfectants and Antiseptics Used in Food, Industrial, Domestic and Institutional Areas-Test Method and Requirements (Phase 2, Step 1)". European Committee for Standardisation Brussels.

Fazlara, A., and Ekhtelat, M. (2012). The disinfectant effects of benzalkonium chloride on some important foodborne pathogens. Am. Eurasian J. Agric. Environ. Sci. 12, 23-29.

Fernandes, S., Gomes, I. B., and Simões, M. (2020). Antimicrobial activity of glycolic acid and glyoxal against Bacillus cereus and Pseudomonas fluorescens. Food Res. Int. 136:109346. doi: 10.1016/j.foodres.2020.109346

Ferreira, C., Pereira, A., Pereira, M., Melo, L., and Simões, M. (2011). Physiological changes induced by the quaternary ammonium compound benzyldimethyl dodecylammonium chloride on Pseudomonas fluorescens. J. Antimicrob. Chemother. 66, 1036-1043. doi: 10.1093/jac/dkr028

Ferreira, C., Rosmaninho, R., Simões, M., Pereira, M., Bastos, M., Nunes, O., et al. (2009). Biofouling control using microparticles carrying a biocide. Biofouling 26, 205-212. doi: 10.1080/08927010903419630

Fleischmann, S., Robben, C., Alter, T., Rossmanith, P., and Mester, P. (2021). How to evaluate non-growing cells-current strategies for determining antimicrobial resistance of VBNC bacteria. Antibiotics 10:115. doi: 10.3390/ antibiotics 10020115

Gerba, C. P. (2015). Quaternary ammonium biocides: efficacy in application. Appl. Environ. Microbiol. 81, 464-469. doi: 10.1128/AEM.02633-14

Grobe, K. J., Zahller, J., and Stewart, P. S. (2002). Role of dose concentration in biocide efficacy against Pseudomonas aeruginosa biofilms. J. Ind. Microbiol. Biotechnol. 29, 10-15. doi: 10.1038/sj.jim.7000256

Highmore, C. J., Warner, J. C., Rothwell, S. D., Wilks, S. A., and Keevil, C. W. (2018). Viable-but-nonculturable Listeria monocytogenes and Salmonella enterica serovar thompson induced by chlorine stress remain infectious. MBio 9, e00540-e00618. doi: 10.1128/mBio.00540-18

Jones, I. A., and Joshi, L. T. (2021). Biocide use in the antimicrobial era: a review. Molecules 26:2276. doi: 10.3390/molecules26082276

Kahrilas, G. A., Blotevogel, J., Stewart, P. S., and Borch, T. (2015). Biocides in hydraulic fracturing fluids: a critical review of their usage, mobility, degradation, and toxicity. Environ. Sci. Technol. 49, 16-32. doi: 10.1021/es503724k

Keep, N., Ward, J., Robertson, G., Cohen-Gonsaud, M., and Henderson, B. (2006). Bacterial resuscitation factors: revival of viable but non-culturable bacteria. Cell. Mol. Life Sci. 63, 2555-2559. doi: 10.1007/s00018-006-6188-2

Kirchhoff, C., and Cypionka, H. (2017). Propidium ion enters viable cells with high membrane potential during live-dead staining. J. Microbiol. Methods 142, 79-82. doi: 10.1016/j.mimet.2017.09.011

Kirschner, A. K., Vierheilig, J., Flemming, H.-C., Wingender, J., and Farnleitner, A. H. (2021). How dead is dead? Viable but non-culturable versus persister cells. Environ. Microbiol. Rep. 13, 243-245. doi: 10.1111/1758-2229.12949
Ko, C.-H., Huang, C.-Y., Hsieh, S.-P., and Kuo, P.-A. (2007). Characterization of two quaternary ammonium chloride-resistant bacteria isolated from papermaking processing water and the biocidal effect on their biofilm formation. Int. Biodeterior. Biodegradation 60, 250-257. doi: 10.1016/j. ibiod.2007.04.003

Kucera, J. (2019). Biofouling of polyamide membranes: fouling mechanisms, current mitigation and cleaning strategies, and future prospects. Membranes 9:111. doi: 10.3390/membranes9090111

Kumar, S. S., and Ghosh, A. R. (2019). Assessment of bacterial viability: a comprehensive review on recent advances and challenges. Microbiology 165, 593-610. doi: 10.1099/mic.0.000786

Li, L., Mendis, N., Trigui, H., Oliver, J. D., and Faucher, S. P. (2014). The importance of the viable but non-culturable state in human bacterial pathogens. Front. Microbiol. 5:258. doi: 10.3389/fmicb.2014.00258

Liwa, A. C., and Jaka, H. (2015). "Antimicrobial resistance: mechanisms of action of antimicrobial agents," in The Battle Against Microbial Pathogens: Basic Science, Technological Advances and Educational Programs. ed. A. Méndez-Vilas (Badajoz: Formatex Research Center), 876-885.

Lomakina, G. Y., Modestova, Y. A., and Ugarova, N. (2015). Bioluminescence assay for cell viability. Biochemistry 80, 701-713. doi: 10.1134/S0006297 915060061

Maillard, J. Y. (2002). Bacterial target sites for biocide action. J. Appl. Microbiol. 92, 16S-27S. doi: 10.1046/j.1365-2672.92.5s1.3.x

Maillard, J.-Y. (2005). Antimicrobial biocides in the healthcare environment: efficacy, usage, policies, and perceived problems. Ther. Clin. Risk Manag. 1, 307-320.

McDonnell, G. (2007). Antiseptics, Disinfection and Sterilization: Types, Action, and Resistance. Washington DC: ASM Press.

Nan, Y. H., Bang, J.-K., and Shin, S. Y. (2009). Design of novel indolicidinderived antimicrobial peptides with enhanced cell specificity and potent anti-inflammatory activity. Peptides 30, 832-838. doi: 10.1016/j.peptides. 2009.01.015

Nguyen, H. T., O’Donovan, L. A., Venter, H., Russell, C. C., McCluskey, A., Page, S. W., et al. (2021). Comparison of two transmission electron microscopy methods to visualize drug-induced alterations of gram-negative bacterial morphology. Antibiotics 10:307. doi: 10.3390/antibiotics10030307

Oliver, J. D. (2010). Recent findings on the viable but nonculturable state in pathogenic bacteria. FEMS Microbiol. Rev. 34, 415-425. doi: 10.1111/j.15746976.2009.00200.x

Parvekar, P., Palaskar, J., Metgud, S., Maria, R., and Dutta, S. (2020). The minimum inhibitory concentration (MIC) and minimum bactericidal concentration (MBC) of silver nanoparticles against Staphylococcus aureus. Biomater. Investig. Dent. 7, 105-109. doi: 10.1080/26415275.2020.1796674

Pati, S. G., and Arnold, W. A. (2020). Comprehensive screening of quaternary ammonium surfactants and ionic liquids in wastewater effluents and lake sediments. Environ Sci Process Impacts 22, 430-441. doi: 10.1039/C9EM00554D

Paulus, W. (2005). Directory of Microbicides for the Protection of Materials: A Handbook. Springer Science \& Business Media.

Reed, R., and Reed, G. (1948). "Drop plate" method of counting viable bacteria. Can. J. Res. 26e, 317-326. doi: 10.1139/cjr48e-020

Ribeiro, M., Simões, L. C., and Simões, M. L. (2018). “Biocides," in Reference Module in Life Sciences. ed. T. H. Schmidt (Amsterdam, The Netherlands: Elsevier), 478-490.

Russo, J. R. (2016). Efficiency of Industrial Disinfectants on Food-Contact Surfaces Sanitation. MSC: University of Porto.

Salton, M. (1968). Lytic agents, cell permeability, and monolayer penetrability. J. Gen. Physiol. 52, 227-252. doi: 10.1085/jgp.52.1.227

Shi, L., Günther, S., Hübschmann, T., Wick, L. Y., Harms, H., and Müller, S. (2007). Limits of propidium iodide as a cell viability indicator for environmental bacteria. Cytometry A 71A, 592-598. doi: 10.1002/cyto.a.20402

Siddiqui, A., Pinel, I., Prest, E., Bucs, S., Van Loosdrecht, M., Kruithof, J., et al. (2017). Application of DBNPA dosage for biofouling control in spiral wound membrane systems. Desal. Water Treat. 68, 12-22. doi: 10.5004/dwt.2017.20370

Signoretto, C., del Mar Lleò, M., Tafi, M. C., and Canepari, P. (2000). Cell wall chemical composition of Enterococcus faecalis in the viable but nonculturable state. Appl. Environ. Microbiol. 66, 1953-1959. doi: 10.1128/aem.66.5.1953-1959.2000

Simões, M., Pereira, M. O., and Vieira, M. J. (2005). Action of a cationic surfactant on the activity and removal of bacterial biofilms formed under different flow regimes. Water Res. 39, 478-486. doi: 10.1016/j.watres.2004.09.018 
Suh, S.-J., Shuman, J., Carroll, L. P., and Silo-Suh, L. (2016). BEEP: An assay to detect bio-energetic and envelope permeability alterations in Pseudomonas aeruginosa. J. Microbiol. Methods 125, 81-86. doi: 10.1016/j.mimet.2016.04.009

Ullah, S. (2011). Biocides in Papermaking Chemistry. Finland: MSc, University of Jyväskylä.

Voget, M., Lorenz, D., Lieber-Tenorio, E., Hauck, R., Meyer, M., and Cieslicki, M. (2015). Is transmission electron microscopy (TEM) a promising approach for qualitative and quantitative investigations of polymyxin B and miconazole interactions with cellular and subcellular structures of Staphylococcus pseudintermedius, Escherichia coli, Pseudomonas aeruginosa and Malassezia pachydermatis? Vet. Microbiol. 181, 261-270. doi: 10.1016/j.vetmic.2015.10.002

Wesgate, R., Grasha, P., and Maillard, J.-Y. (2016). Use of a predictive protocol to measure the antimicrobial resistance risks associated with biocidal product usage. Am. J. Infect. Control 44, 458-464. doi: 10.1016/j.ajic. 2015.11.009

Wideman, N. E., Oliver, J. D., Crandall, P. G., and Jarvis, N. A. (2021). Detection and potential virulence of viable but non-culturable (VBNC) Listeria monocytogenes: a review. Microorganisms 9:194. doi: 10.3390/microorganisms9010194

Williams, T. M., and McGinley, H. R. (2010). "Deactivation of industrial water treatment biocides", in CORROSION 2010. OnePetro.

Yasir, M., Dutta, D., and Willcox, M. D. (2019). Mode of action of the antimicrobial peptide Mel4 is independent of Staphylococcus aureus cell membrane permeability. PLoS One 14:e0215703. doi: 10.1371/journal. pone. 0215703

Ziklo, N., Bibi, M., and Salama, P. (2021). The antimicrobial mode of action of Maltol and its synergistic efficacy with selected cationic surfactants. Cosmetics 8:86. doi: 10.3390/cosmetics8030086

Conflict of Interest: The authors declare that the research was conducted in the absence of any commercial or financial relationships that could be construed as a potential conflict of interest.

Publisher's Note: All claims expressed in this article are solely those of the authors and do not necessarily represent those of their affiliated organizations, or those of the publisher, the editors and the reviewers. Any product that may be evaluated in this article, or claim that may be made by its manufacturer, is not guaranteed or endorsed by the publisher.

Copyright (๑) 2022 Barros, Melo and Pereira. This is an open-access article distributed under the terms of the Creative Commons Attribution License (CC BY). The use, distribution or reproduction in other forums is permitted, provided the original author(s) and the copyright owner(s) are credited and that the original publication in this journal is cited, in accordance with accepted academic practice. No use, distribution or reproduction is permitted which does not comply with these terms. 